\title{
Handling Qualities Analysis of an Unmanned Aircraft Vehicle for Agricultural Spraying
}

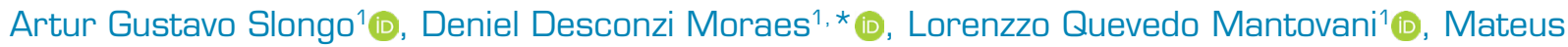 \\ Schmitz Venturini ${ }^{1} \mathbb{D}$ \\ 1.Universidade Federal de Santa Maria - Centro de Tecnologia - Departamento de Engenharia Mecânica - Santa Maria/RS - Brazil. \\ *Correspondence author: d.desconzi@gmail.com
}

\section{ABSTRACT}

The use of unmanned aircraft vehicles (UAVs) for the most diverse aeronautic missions is a reality. Then, with the rise of precision agriculture (PA), the viability of the incorporation of this technology in the countryside on both big and small proprieties is under study. This work aims to analyze the handling qualities of an UAV with a mission of pest control chemical spraying. With this objective, aircraft data was used to analyze the eigenvalues of the aircraft modes. Then, the impact of mass and inertia variation during its mission was studied. Also, the longitudinal and latero-directional dynamics were evaluated based on the Cooper-Harper scale. The results found indicate that all aircraft modes are stable for both full hopper and empty hopper conditions. Moreover, the determined handling quality grades of the UAV in the Cooper-Harper scale indicate the need for some correction applied by the pilot during flight.

Keywords: Agricultural aircraft; Agriculture; Drone; Handling qualities; Remote handling; Flight simulation.

\section{INTRODUCTION}

The development of remotely piloted aircraft technologies has experienced intense growth during the last years. Covering both civilian and military areas, unmanned aerial vehicles (UAVs) can assist with tasks already performed by other technologies, with advantages such as quicker responses, lower costs and more versatility. In Brazil, since the last decade, UAVs are used to aid agriculture, both in spraying pesticides in crops, as well as in precision agriculture. The area that currently sees the greatest growth within agribusiness is the acquisition of aerial images using this type of aircraft. From the acquired images and the use of computer vision techniques, the rural producer receives important information for decision making in the countryside (Jorge et al. 2011).

As defined by the Brazilian Commission for Precision Agriculture (CBAP 2013), precision agriculture is "an agricultural management system based on the spatial and temporal variation of the productive unit and aims at increasing the economic return, sustainability and minimizing the effect on the environment". In addition to the decision-making process, in precision agriculture, there is a need to distribute crop protection products throughout a region infected by a pest or suffering by other condition, as well as to deposit pesticides over the crop to prevent these same problems. Most of these activities are carried out from land-based machines; however, they cause damage to the culture itself through kneading (Oliveira et al. 2014). In order to solve this problem, agricultural aviation is employed since it is both more efficient and faster when compared to land-based machines. However, there are considerable risks for both the pilot and the operation. The pilot faces several flights at low altitude, which increases the risk

Received: Feb. 02, 2020 | Accepted: Oct. 05, 2020

Peer Review History: This is a peer reviewed version of selected paper presented at the $2^{\circ}$ Congresso Aeroespacial Brasileiro occurred in 16 -19 September of 2019 at Universidade Federal de Santa Maria, Santa Maria/RS, Brazil.

Section Editor: André Luis da Silva

This is an open access article distributed under the terms of the Creative Commons license. 
of accidents due to the low visibility and short reaction time. Further, the operation suffers from its dependence on the weather, as operations on rainy days and at night are not allowed for safety reasons.

Thus, seeking to complement the Brazilian agriculture tendencies of new technical solutions to improve production efficiency without increasing acreage, recent work by Slongo et al. (2019) developed a conceptual UAV design that has the capability of actuating in the niche among autopropelled machines and conventional spraying aircraft. The employment of UAV allows the adoption of new possible solutions, which were not feasible before due to the pilot safety and other piloted flight aspects. The capacity of performing operations in low visibility conditions - such as at night - allows both the operating period to increase and quicker responses to be executed, which can prevent pest proliferation in their beginning. In addition to an increased performance capability, being a high precision system allows a reduction in both environmental impact, costs of operation when compared with standard application methods and reduce the amount of pesticide drifting to neighboring crop fields (Lan and Chen 2018; Anand and Goutam 2019).

Even though these unmanned systems have the potential to work in conjunction of autonomous flight systems, the current regulations presented by the National Civil Aviation Agency (ANAC) in the document Regulamento da Aviação Civil Especial (RBAC-E No. 94) forbid the autonomous operation of UAVs in the Brazilian territory. In addition, the possibility of quick response to pests utilizing an UAV is one of the main advantages of this technology in comparison with regular agricultural aviation. Thus, the thorough and in advance planning needed for autonomous operation is not in the best interest of the farmer in these cases. In view of the presented issues, the remotely piloted operation of the aircraft constituting a man-in-the-loop control is considered is this work.

The ability of the pilot to control the aircraft's movements can be described by the aircrafts' handling qualities. As defined by Harper and Cooper (1986, p. 2), the handling qualities are "those qualities or characteristics of an aircraft that govern the ease and precision with which a pilot is able to perform the tasks required in support of an aircraft role".

Due to the presence of a pilot in the operation of the UAV, the analysis of the handling qualities of the aircraft are of interest of the designer, since they will guide the developments of control systems and the pilot vehicle interface (PVI) of the aircraft (Baughman and Longeauay 2015). In addition, poor handling qualities indicate failures in the design process, thus being necessary to reevaluate the aircraft main characteristics.

As presented by Cook (2011), Cooper and Harper are also the creators of one of the most utilized ways to evaluate the handling qualities of an aircraft, the Cooper-Harper scale. To use this scale, it is necessary to determine the damping and period of the short period, phugoid, roll, spiral and Dutch roll modes.

The complete UAV flight dynamics is used to determine the required parameters aforementioned, considering the cruise flight phase. Hence, it is possible to obtain the linearized matrices of the system at the set operation conditions, which allows the system poles to be found. Consequently, the damping and period of each mode can be determined.

However, the Cooper-Harper scale was designed for the analysis of manned aircraft operations; thus, it is important to be cautious when adapting the analysis for UAVs. So far, some works have dealt with the analysis of UAV handling qualities, but none of them has been successful in determining a new standard that overwrites the Cooper-Harper scale.

Williams (2003) discussed a proposed standard specifying the requirements for UAV handling qualities. Based on manned aircrafts standards, the work studied the differences between UAV and traditional aircraft in terms of handling qualities based on a systems engineering approach. The paper discusses broadly a "new" standard for handling qualities evaluation of UAVs; however, the differences related to primary and secondary flight control systems, data link time delays, system failure states and flight display requirements, which are all characteristics that are not dealt with in a preliminary design phase and so, are not consider in the present work.

On the flight display requirements topic, Cummings et al. (2006) present a new evaluation tool for subjectively assessing unmanned vehicle displays by shifting emphasis away from evaluating the physical control of an aircraft to evaluating how well the displays support basic operator information processing. The justification of the authors is that, in remotely controlled flight, the control of the aircraft is mostly performed by the on-board computer, and the great part of the handling qualities rest on the interface between pilot and aircraft and the capacity of the pilot to analyze information and make decisions. This tool is called the modified Cooper-Harper for unmanned vehicles displays and, even though it is useful on evaluating the interaction between 
the pilot and the UAV, it does not substitute the need for evaluating the physical control of the aircraft, given that at any time the pilot may have to take manual control over the aircraft operation.

In addition, Foster and Bowman (2005) present a discussion of dynamic stability and handling qualities of small unmannedaerial-vehicles. The authors show that, for small UAVs with wingspans from 0.6 to $1.2 \mathrm{~m}$, the requirements for short-period mode natural frequency of larger aircraft are too tight and do not represent the correct evaluation of these aircraft. However, the aircraft analyzed in this work does not fit in this category, so it is not possible to neglect the result of the Cooper-Harper scale evaluation.

Lastly, Baughman and Longeauay (2015) provide an approach to determine the Cooper-Harper evaluation for unmanned systems. In their study case, they considered a pilot-in-the-loop oscillation, that way, even though the system may operate in high levels of autonomous flight, there are situations where it is necessary, or advised, that the pilot intervenes, for no feedback loop or computer algorithm can deliver the same qualitative feedback as a pilot. Furthermore, Baughman and Longeauay's (2015) approach considers a three-phased analysis to conduct a handling qualities evaluation. The first and second phases are a qualitative assessment of the aircraft handling in a docile environment and an exploration of high-gain and high-bandwidth control of the aircraft, both of which are not applicable to an aircraft preliminary design phase. The third phase considers an evaluation using the Cooper-Harper rating scale where, given adequate criteria, performance is assessed as well as workload and pilot compensation in order to yield a Cooper-Harper rating.

In view of the information presented, the Cooper-Harper approach was chosen for this work given the design phase in which the aircraft finds itself and the lack of a better alternative for handling qualities evaluation in this phase. In addition, the CooperHarper rating of the aircraft is complementary to other proposed evaluations of UAVs handling qualities, justifying its utilization.

\section{METHODOLOGY}

\section{Aircraft Parameters}

The required information to perform the UAV flying and handling qualities were extracted from the finalized aircraft conceptual project (Slongo et al. 2018). The aircraft model made in the SolidWorks software provided both the moments of inertia and the position of the center of gravity (CG) of the aircraft for the two distinct cases analyzed. The first case considers a full hopper, which is the situation of maximum takeoff weight (MTOW), and the second case considers an empty hopper - end of mission. The frontal isometric view of the aircraft's computer-aided design (CAD) model can be seen in Fig. 1.

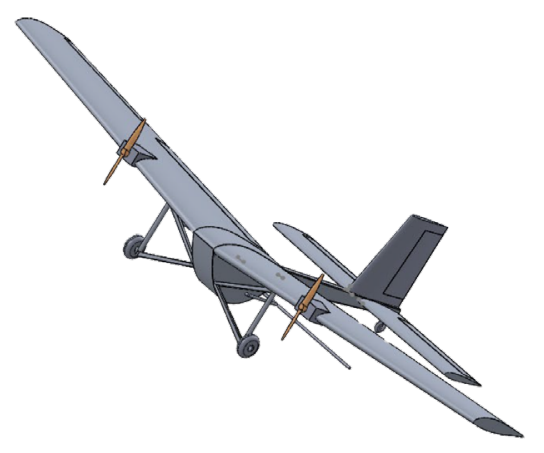

Figure 1. Frontal isometric view of the aircraft's CAD model.

The data used is:

- Payload: $100 \mathrm{~kg}$

- Fuel: 12 kg;

- Propulsion system mass: $11.594 \mathrm{~kg}$;

- Fuselage and equipment mass: $157.366 \mathrm{~kg}$;

- Aircraft's empty mass: $168.96 \mathrm{~kg}$; 
- $\quad$ MTOW: $280.96 \mathrm{~kg}$;

- Wing area: $10.24 \mathrm{~m}^{2}$;

- Wingspan: $7.85 \mathrm{~m}$;

- Mean aerodynamic chord: $1.13 \mathrm{~m}$.

The UAV's inertia matrix, $I_{U A V}$, with full and empty hopper, are shown in Eq. 1 and Eq. 2, respectively.

$$
\begin{aligned}
I_{U A V_{\text {full }}} & =\left[\begin{array}{ccc}
317.3513 & 5.9670 & 10.9556 \\
5.9670 & 126.6032 & -0.8662 \\
10.9556 & -0.8662 & 391.0695
\end{array}\right] \\
I_{U A V_{\text {empty }}} & =\left[\begin{array}{ccc}
306.7406 & 6.1078 & 9.5168 \\
6.1078 & 115.5113 & 0.2427 \\
9.5168 & 0.2427 & 390.3372
\end{array}\right]
\end{aligned}
$$

The CG is positioned $0.21 \mathrm{~m}$ backwards from the aerodynamic center $(\mathrm{AC})$ in the full hopper case. For the empty hopper case, the CG is positioned $0.19 \mathrm{~m}$ from the AC, also backwards.

During earlier phases of the project, the propulsion system was defined as two piston engines with an air-cooling system, which can deliver up to $21.5 \mathrm{hp}$ each. Hence, the propulsion system can deliver $947.78 \mathrm{~N}$ of thrust, considering the propeller efficiency.

\section{Aerodynamic stability and control derivatives}

Aerodynamic stability and control derivatives were obtained using the Advanced Aircraft Analysis Software (AAA), as described in the aircraft conceptual project (Slongo et al. 2018). Table 1 shows these aerodynamic derivatives.

Table 1. Aerodynamic stability and control derivatives.

\begin{tabular}{cccc}
\hline $\begin{array}{c}\text { Stability and control } \\
\text { derivative }\end{array}$ & $\begin{array}{c}\text { Dimensionless } \\
\text { value }\end{array}$ & $\begin{array}{c}\text { Stability and control } \\
\text { derivative }\end{array}$ & $\begin{array}{c}\text { Dimensionless } \\
\text { value }\end{array}$ \\
\hline$C L_{0}$ & 0.500 & $C l_{\beta}$ & -0.1912 \\
$C D_{0}$ & 0.0100 & $C l_{\delta r}$ & 0.0109 \\
$C Y_{\beta}$ & -0.2120 & $C n_{r}$ & -0.0302 \\
$C Y_{\delta r}$ & 0.1098 & $C L_{q}$ & 7.1453 \\
$C m_{\delta e}$ & -1.0977 & $C D_{\delta e}$ & 0.0586 \\
$C l_{r}$ & 0.1076 & $C Y_{r}$ & 0.0815 \\
$C n_{\beta}$ & -0.0016 & $C m_{\alpha}$ & -2.0417 \\
$C L^{\alpha}$ & 4.9420 & $C n_{0}$ & -0.0006 \\
$C D_{q}$ & 0.0000 & $C n_{\delta a}$ & 0.0000 \\
$C Y_{\beta}$ & $C L_{\dot{\alpha}}$ & -0.0022 \\
$C m_{0}$ & -0.0066 & $C Y_{0}$ & 1.9320 \\
$C l_{0}$ & -0.1100 & $C Y_{\delta a}$ & 0.0000 \\
$C l_{\beta \alpha}$ & 0.0000 & $C m_{\dot{\alpha}}$ & 0.0000 \\
$C n_{p}$ & 0.1619 & $C l_{p}$ & -4.0556 \\
$C L_{\delta e}$ & -0.0390 & $C n_{\beta}$ & -0.4339 \\
$C D_{\alpha}$ & 0.5229 & $C n_{\delta r}$ & 0.0412 \\
$C Y_{p}$ & 0.9386 & - & -0.0411 \\
$C m_{p}$ & -0.1098 & -10.9033 & - \\
\hline
\end{tabular}




\section{Definition of Flight Simulation Conditions}

Flight conditions depend on the chemical being carried on the hopper. Thus, it is necessary to consider several cases to which the aircraft can be submitted. Among the simulated conditions, the full and the empty hopper cases were both analyzed with an average cruise speed. These two cases represent the beginning and ending of a spraying operation. Hence, it is possible to evaluate how the CG and inertia changes affect the handling qualities.

Due to the need for operating at low speed and high weight conditions, the aircraft project includes the capability of tilting the engines to increase lift. However, the angle between the thrust vector and the aircraft reference system is considered zero in these preliminary simulations. The simulated flight condition is:

- Average cruise speed: $68 \mathrm{~km} / \mathrm{h}$;

- Spraying height: $4 \mathrm{~m}$;

- Engine inclination: $0^{\circ}$;

- Mass:

- Full hopper: $280 \mathrm{~kg}$;

- Empty hopper: $180 \mathrm{~kg}$.

According to recent work by Slongo et al. (2019), the aircraft optimal speed for spraying ranges from 60 to $80 \mathrm{~km} / \mathrm{h}$. Likewise, the spraying height is $4 \mathrm{~m}$. With this information, it is possible to linearize the aircraft dynamics around an operating condition.

\section{Reference Systems and Attitude Parameterization}

The equation development considers both the inertial reference frame and the body reference frame. An arbitrary point on the ground, such as a runway threshold, can be used as the inertial frame origin. The inertial frame axes can be defined as: $Z_{l}$ points upwards, $X_{l}$ is aligned with an arbitrary on the horizon, while $Y_{l}$ completes the orthogonal system.

The body reference frame, which is a rotating frame, has the $X_{e}$ axis pointing through the aircraft nose, $Y_{e}$ axis pointing towards the starboard wing and the $Z_{e}$ lays in the aircraft symmetry plane, being negative above the aircraft. Its origin is set at the aircraft's CG. The body reference frame is shown in Fig. 2.

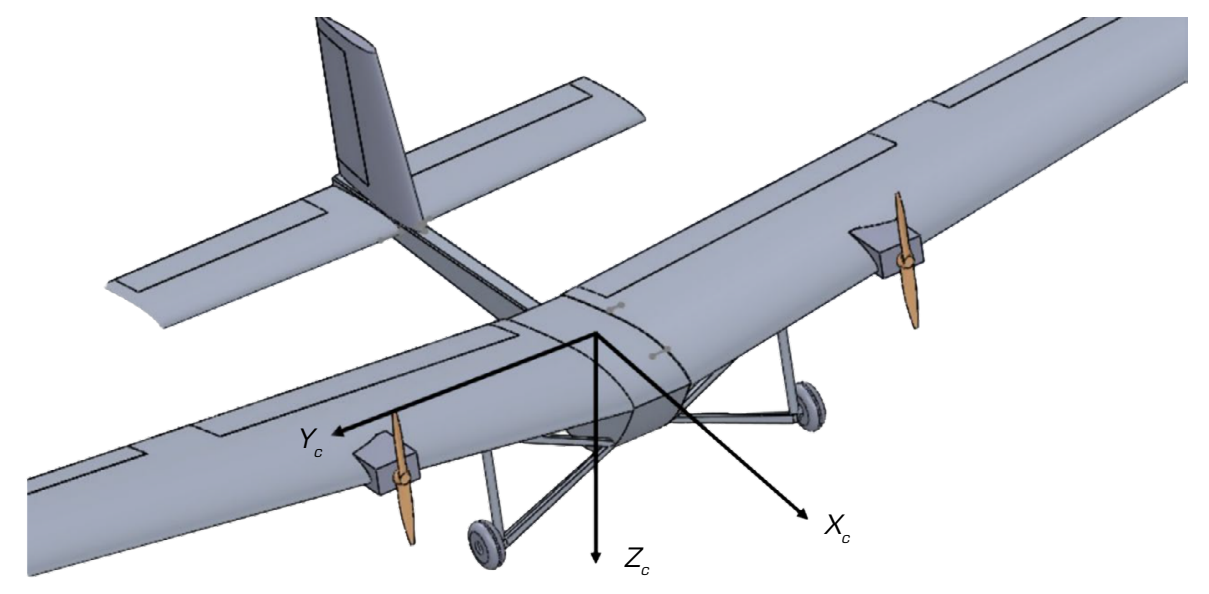

Figure 2. Body reference frame.

For the attitude parameterization, which is the angular position representation of the frames, Euler angles were used. According to Tewari (2007), three successive rotations can be used to describe any spatial orientation, and elementary rotation matrices can be used to represent it. The adopted sequence of rotation is 3-2-1; hence, the system first rotates around the $Z$-axis, then around the $Y$-axis and, lastly, around the $X$-axis. Therefore, a rotation matrix from the inertial system to the body system $\left(R_{l}^{B}\right)$ is shown in Eq. 3, while Fig. 3 illustrates this rotation sequence. 


$$
R_{I}^{B}=R_{1}(\phi) R_{2}(\theta) R_{3}(\psi)=\left[\begin{array}{ccc}
1 & 0 & 0 \\
0 & \cos \phi & \sin \phi \\
0 & -\sin \phi & \cos \phi
\end{array}\right]\left[\begin{array}{ccc}
\cos \theta & 0 & -\sin \theta \\
0 & 1 & 0 \\
\sin \theta & 0 & \cos \theta
\end{array}\right]\left[\begin{array}{ccc}
\cos \psi & \sin \psi & 0 \\
-\sin \psi & \cos \psi & 0 \\
0 & 0 & 1
\end{array}\right]
$$

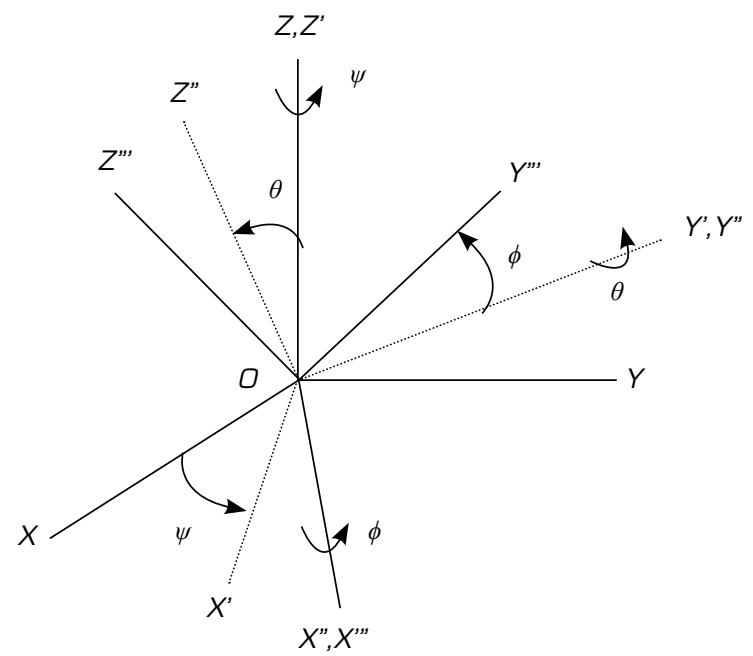

Figure 3. Euler Angle rotation sequence (Tewari 2007).

\section{Aircraft Mathematical Model}

In order to determine the eigenvalues of the system and, consequently, the handling qualities, it is necessary to mathematically model the aircraft in the first place. One of the possibilities is to use transfer functions, which represent each of the aircraft modes. Another is to use the aircraft complete model. The analysis presented here considers the complete model, which was then linearized around the point of interest.

Thus, 12 equations are used to describe both the translational and rotational dynamics of the rigid body. Six of these equations represent the translations of the body, which can be written in the inertial system and then separated into three dynamic equations (Eq. 4) and three kinematic equations (Eqs. 5-7 or Eq. 8). To obtain the three dynamic equations of the aircraft, the linear momentum equation can be derived with respect to the inertial frame, which leads to:

$$
\dot{V}=\frac{F_{e x t}}{m}-\omega \times V
$$

where $V$ represents the translational velocity vector, $V=[u v w]^{\mathrm{T}}, \omega$ represents the angular velocity vector written in the body reference frame with respect to the inertial frame, $\omega=\left[\begin{array}{ll}p & r\end{array}\right]^{T}, F_{\text {ext }}$ the external forces vector written in the body reference frame and $m$ is the aircraft's mass. However, the aircraft dynamics is usually written as a function of the true airspeed ( $\left.V_{a}\right)$, and both attack angle $(\alpha)$ and sideslip angle $(\beta)$. Thus, three modified equations are obtained, as follows:

$$
\begin{gathered}
\dot{V}_{a}=\frac{(u \dot{u}+v \dot{v}+w \dot{w})}{V_{a}} \\
\dot{\alpha}=\frac{u+\dot{w}-w \dot{u}}{u^{2}+w^{2}}
\end{gathered}
$$




$$
\dot{\beta}=\frac{V_{a} \dot{v}-\dot{V}_{a} v}{V_{a}^{2} \sqrt{V_{a}-\frac{v^{2}}{V_{a}^{2}}}}
$$

Then, the translational kinematic equations can be written in the inertial frame as:

$$
\left[\begin{array}{c}
\dot{X} \\
\dot{Y} \\
\dot{Z}
\end{array}\right]=R_{I}^{B^{T}} \dot{V}
$$

For the rotation equations, the angular momentum equation is derived with respect to the inertial frame:

$$
\dot{\omega}=I_{U A V}^{-1}\left[\tau-\omega \times\left(I_{U A V} \omega\right)\right]
$$

in which $\tau$ indicates the external torques, and $I_{U A V}$ is its inertial matrix at the point of interest.

After, the attitude with respect to the inertial frame is obtained through the rotational kinematic equations, in the form:

$$
\begin{gathered}
\dot{\phi}=p+[r \cos (\phi)+q \sin (\phi)] \tan (\theta) \\
\dot{\theta}=q \cos (\phi)-r \sin (\phi) \\
\dot{\psi}=\sec (\theta)[r \cos (\phi)+q \sin (\phi)]
\end{gathered}
$$

\section{Eigenvalues and Handling Quality}

With the aircraft's complete dynamics and the operation point, it is possible to obtain the linearized matrices of the system. Moreover, with the matrices, it is possible to obtain the eigenvalues for the used condition to analyze the UAV stability. With it, both the modes frequency can be obtained through Eq. 13 and Eq. 14, where $\sigma$ and $\xi$ indicate the eigenvector real and imaginary part, respectively.

$$
\begin{gathered}
\omega=\sqrt{\sigma^{2}+\gamma^{2}} \\
\xi=\frac{\sigma}{\omega^{2}}
\end{gathered}
$$

\section{Longitudinal Dynamic}

To analyze the handling qualities of the longitudinal dynamic, it is necessary to determine the $n_{\alpha}$ factor, which is the normal load factor per unit angle of attack, given by Eq. 15: 


$$
n_{\alpha}=\frac{V_{e}}{g T_{\theta_{2}}}
$$

The $T_{\theta 2}$ variable represents the incidence lag, and its value shall be above $0.5 \mathrm{~s}$ for the aircraft to have a good response time (Cook 2011). With the natural frequency of the short period and $n_{a}$, it is possible to analyze Fig. 4 and determine the short period handling level.

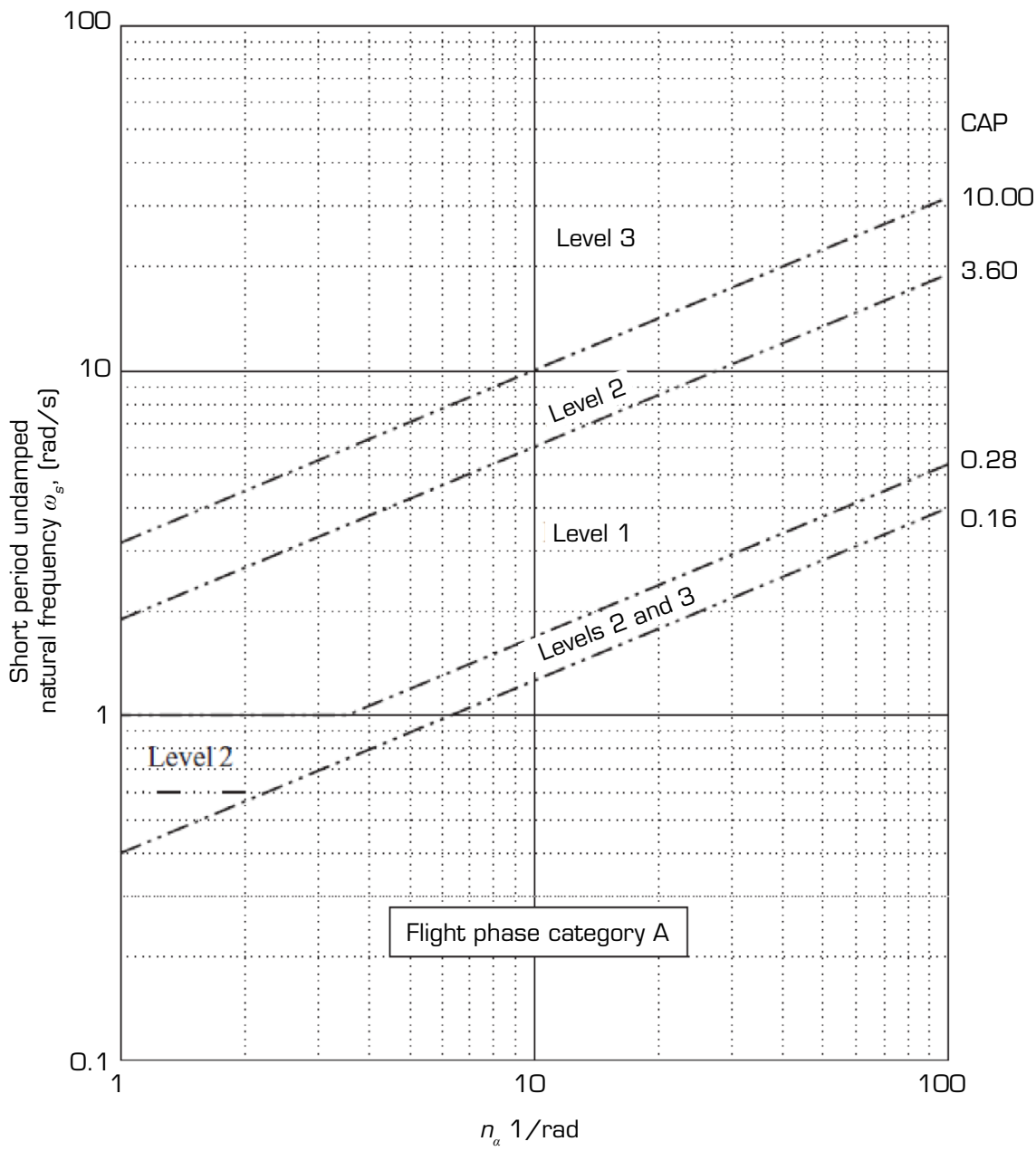

Figure 4. Handling qualities as a function of $\omega_{S}$ (Cook 2011).

The short period can also be evaluated based on its damping coefficient, as shown in Table 2 .

Table 2. Flight handling quality of the short period as a function of $\zeta$.

\begin{tabular}{cccccc}
\hline \multirow{2}{*}{ Flight phase } & \multicolumn{2}{c}{ Level 1 } & \multicolumn{2}{c}{ Level 2 } & Level 3 \\
\cline { 2 - 5 } & $\zeta_{\mathrm{s}} \min$ & $\zeta_{\mathrm{s}} \max$ & $\zeta_{\mathrm{s}} \min$ & $\zeta_{\mathrm{s}} \max$ & $\zeta_{\mathrm{s}}$ min \\
\hline Cruise flight & 0.30 & 2.00 & 0.20 & 2.00 & 0.10 \\
\hline
\end{tabular}

Adapted from Cook (2011).

For the phugoid mode, handling qualities can be evaluated based on the damping coefficient, which shall be above $10 \%$ of the short period damping coefficient (Cook 2011). Thus, its classification is: 
- Level 1: Damping higher than 0.04;

- Level 2: Null damping;

- Level 3: Unstable mode.

\section{Lateral directional dynamics}

For the roll mode, handling qualities is based on the time constant. For a cruise flight, according to Cook (2011):

- Level 1: Time constant higher than $1.4 \mathrm{~s}$;

- Level 2: Time constant ranging from 1.4 to $3 \mathrm{~s}$.

For the Dutch Roll mode, the analyzed variables are natural frequency, $\omega_{n_{d}}$ damping coefficient, $\zeta_{d^{\prime}}$ and its multiplication, $\omega_{n_{d}} \zeta_{d^{\prime}}$ For the cruise flight condition (Cook 2011), the aircraft is classified as:

- Level 1:

- $\omega_{n_{d}}>0.5$

- $\zeta_{d}>0.08$

- $\omega_{n_{d}} \zeta_{d}>0.15$

- Level 2:

- $0.5>\omega_{n_{d}}>0.4$;

- $0.08>\zeta_{d}>0.02$;

- $0.15>\omega_{n_{d}} \zeta_{d}>0.05$;

- Level 3:

- $0.5>\omega_{n_{d}}<0.4$;

- $0.02>\zeta_{d}$;

- $0.05>\omega_{n_{d}} \zeta_{d}$;

For the spiral mode, only its time constant is analyzed. For cruise flight phase, as presented in Cook (2011):

- Level 1: Time constant higher than $28.9 \mathrm{~s}$;

- Level 2: Time constant ranging from 28.9 to $11.5 \mathrm{~s}$;

- Level 3: Time constant ranging from 11.5 to $7.2 \mathrm{~s}$.

\section{Cooper-Harper Scale}

It is possible to identify the UAV handling qualities based on the Cooper-Harper scale using both the frequency and damping coefficients, which connects the aircraft response with the pilot reactions and perception. Such scale evaluates the flight handling qualities in several flight phases, with grades that range from 1 to 10 , being 1 the best possible. This information is presented in Table 3.

Table 3. Cooper-Harper scale conversion. Flight quality levels

\begin{tabular}{l|l|l|l|l|l|l|l|l|l|l|c}
\hline & \multicolumn{3}{|c|}{ Level 1 } & \multicolumn{3}{c|}{ Level 2 } & \multicolumn{3}{c|}{ Level 3 } & \multicolumn{3}{c}{ Below level 3 } \\
\hline Cooper-Harper Scale & 1 & 2 & 3 & 4 & 5 & 6 & 7 & 8 & 9 & 10 \\
\hline Adapted from Cook [2011]. & & & & &
\end{tabular}

Adapted from Cook (2011).

\section{RESULTS}

\section{Full Hopper}

Linearizing the UAV dynamics around the aforementioned operation point allows the aircraft eigenvalues to be obtained. The linearized matrix of the longitudinal dynamics $A_{\text {Longriul }}$ is given in Eq. 16: 


$$
A_{\text {Long }_{\text {Full }}}=\left[\begin{array}{ccccc}
-0.0374 & 0.4757 & -9.6643 & -2.8774 & -0.001 \\
-0.6511 & -2.2484 & -1.6649 & 16.7078 & 0.009 \\
0.0000 & 0.0000 & 0.0000 & 1.0000 & 0.0000 \\
0.2147 & -1.0398 & 0.0000 & -7.3798 & -0.0000 \\
0.1697 & -09855 & 18.8889 & 0.0000 & 0.0000
\end{array}\right]
$$

With the $A_{\text {Long Full }_{\text {Ful }}}$ matrice, it is possible to obtain the eigenvalues for each longitudinal modes of the aircraft — short period and phugoid. Since the eigenvalues are negative, both modes are stable; hence, it returns spontaneously to equilibrium. The short period mode has a higher frequency when compared to the other modes; thus, it has a shorter period, and a higher damping coefficient. Table 4 shows both the short period and phugoid modes frequency, damping coefficient and eigenvalues.

Table 4. Frequency and damping of the longitudinal modes with full hopper.

\begin{tabular}{cccc}
\hline Mode & Frequency & Damping ratio & Eigenvalues \\
\hline Short period & $5.8700 \frac{\mathrm{rad}}{\mathrm{s}}$ & 0.8260 & $-4.7983 \pm 3.522 i$ \\
Phugoid & $0.5750 \frac{\mathrm{rad}}{\mathrm{s}}$ & 0.0598 & $-0.0344 \pm 0.5741 i$ \\
\hline
\end{tabular}

For the lateral-directional dynamics, the analyzed modes are roll, spiral, and Dutch-roll. The matrix $A_{\text {Lat }_{\text {Full }}}$ has the linearized values obtained for the lateral-directional dynamics (Eq. 17).

$$
A_{\text {Lat }_{\text {full }}}=\left[\begin{array}{ccccc}
0.0245 & 9.6644 & 0.0000 & 3.4124 & -18.7682 \\
0.0000 & 0.0000 & 0.0000 & 1.0000 & 0.1722 \\
0.0000 & 0.0000 & 0.0000 & 0.0000 & 1.0147 \\
-0.5573 & 0.0000 & 0.0000 & -5.6738 & 1.3924 \\
0.0823 & 0.0000 & 0.0000 & -0.5714 & -0.2803
\end{array}\right]
$$

With $A_{\text {Lat }_{\text {Full }}}$, the values of damping and natural frequency were determined, as shown in Table 5. Roll is a nonoscillatory high-frequency mode when compared to the other modes. On the other hand, Dutch-roll has a low damping and an imaginary component in its eigenvalues - it is an oscillatory mode. Spiral has a positive real eigenvalue; thus, it is unstable. However, it is common for aircraft to have this unstable mode, usually with a high time constant, since the pilot can easily correct it.

Table 5. Frequency and damping of the lateral-directional modes with a full hopper.

\begin{tabular}{cccc}
\hline Mode & Frequency & Damping factor & Eigenvalue \\
\hline Roll & $5.5600 \frac{\mathrm{rad}}{\mathrm{s}}$ & 1.000 & $-5.5614 \pm 3.522 i$ \\
Spiral & $0.0445 \frac{\mathrm{rad}}{\mathrm{s}}$ & - & 0.0445 \\
Dutch-roll & $1.9100 \frac{\mathrm{rad}}{\mathrm{s}}$ & 0.1080 & $-0.2064 \pm 1.912 i$ \\
\hline
\end{tabular}

\section{Flight Handling Qualities With a Full Hopper}

The UAV has an incidence lag of $0.488 \mathrm{~s}$, which meets its requirement for the longitudinal dynamics. The frequency and damping ratio of the short period are: 
- Natural frequency $\left(n_{\alpha}=3.9493\right.$ and $\left.\omega_{\text {Spc }}=5.85 \frac{\mathrm{rad}}{\mathrm{s}}\right)$ : Level 2;

- Damping $(\zeta=0.826)$ : Level 1.

Although the aircraft does not meet its requirement of damping lower than $10 \%$ of the short period for the phugoid mode, its value $(\zeta=0.0881)$ is considered Level 1 .

The lateral-directional roll mode has a time constant of $0.176 \mathrm{~s}$, which is considered as Level 1 . Dutch-roll mode is classified as Level 1 for cruise phases, with values of:

- Natural frequency $\left(\omega_{S_{D R}}\right): 1.91 \frac{\mathrm{rad}}{\mathrm{s}}$;

- Damping coefficient $\left(\zeta_{D R}\right): 0.108$;

- $\omega_{S_{D R}} \zeta_{D R}: 0.20628$.

The spiral mode is classified as Level 2 for the cruise flight phase since it has a time constant equal to $22.5 \mathrm{~s}$. In the end, the flight handling qualities are translated to the Cooper-Harper scale, with the UAV obtaining Levels 4, 5 and 6, according to Table 3.

\section{Empty hopper}

For the case with an empty hopper, the same procedure mentioned before was followed. The aircraft eigenvalues were determined linearizing the UAV dynamics around its operating point. The linearized matrix for the longitudinal dynamics with an empty hopper is given by Eq. 18 .

$$
A_{\text {Long }_{\text {empty }}}=\left[\begin{array}{ccccc}
-0.0260 & 0.1502 & -9.7776 & -1.2198 & -0.0001 \\
-0.7790 & -3.3663 & -0.7539 & 15.8317 & 0.0009 \\
0.0000 & 0.0000 & 0.0000 & 1.0000 & 0.0000 \\
0.1157 & -1.2724 & 0.0000 & -8.0884 & -0.0000 \\
0.0768 & -0.9970 & 18.8889 & 0.0000 & 0.0000
\end{array}\right]
$$

It is possible to obtain the eigenvalues for each of the longitudinal modes of the UAV with $A_{\text {Latgenpyy }}$. Since both eigenvalues are negative, both modes are stable and the aircraft can naturally return to equilibrium. As mentioned before, the short period mode has the highest frequency and the highest damping. Table 6 presents the frequency, damping coefficient and eigenvalues for the short period and phugoid modes of the cruise flight phase with an empty hopper.

Table 6. Frequency and damping of the longitudinal modes with an empty hopper.

\begin{tabular}{cccc}
\hline Mode & Frequency & Damping & Eigenvalues \\
\hline Short period & $6.89000 \frac{\mathrm{rad}}{\mathrm{s}}$ & 0.83200 & $-5.74000 \pm 3.83000 i$ \\
Phugoid & $0.53300 \frac{\mathrm{rad}}{\mathrm{s}}$ & 0.00989 & $-0.00527 \pm 0.53300 i$ \\
\hline
\end{tabular}

Roll, spiral and Dutch-roll modes are analyzed for the lateral-directional dynamics. The matrix $A_{\text {Lat } \text { Enpy }}$ has the linearized values for the lateral-directional dynamics of the cruise flight phase with an empty hopper (Eq. 19).

$$
A_{\text {Lat }_{\text {empty }}}=\left[\begin{array}{ccccc}
0.0925 & 9.7777 & 0.0000 & 1.7724 & -19.0716 \\
0.0000 & 0.0000 & 0.0000 & 1.0000 & 0.0771 \\
0.0000 & 0.0000 & 0.0000 & 0.0000 & 1 . \\
-0.5769 & 0.0000 & 0.0000 & -5.8669 & 1.4418 \\
0.0841 & 0.0000 & 0.0000 & -0.5562 & -0.2848
\end{array}\right]
$$


With this matrix, both the damping and the natural frequency were found, as shown in Table 7. The spiral mode has a positive real eigenvalue; thus, it is an unstable mode again. Moreover, Dutch-roll mode has a small damping and an imaginary component in its eigenvalue.

Table 7. Frequency and damping of the lateral-directional modes for an empty hopper.

\begin{tabular}{cccc}
\hline Mode & Frequency & Damping factor & Eigenvalue \\
\hline Roll & $5.89000 \frac{\mathrm{rad}}{\mathrm{s}}$ & 1.00000 & -5.89000 \\
Spiral & $0.00914 \frac{\mathrm{rad}}{\mathrm{s}}$ & - & 0.00914 \\
Dutch-Roll & $1.89000 \frac{\mathrm{rad}}{\mathrm{s}}$ & 0.04600 & $-0.08680 \pm 1.89000 i$ \\
\hline
\end{tabular}

\section{Flight handling qualities with an empty hopper}

For the longitudinal dynamics with an empty hopper, the aircraft has an incidence lag of $0.331 \mathrm{~s}$, which, again, meets its requirements. The flight handling quality of the short period, in accordance with Cook (2011), is:

- Natural frequency $\left(n_{\alpha}=5.8169\right.$ and $\left.\omega_{s p c}=6.89 \frac{\mathrm{rad}}{\mathrm{s}}\right)$ : Level 2;

- Damping $(\zeta=0.832)$ : Level 1 .

Now, the UAV meets the requirement of the phugoid damping being lower than $10 \%$ of the short period mode. With damping of 0.00989 , it is classified as Level 2 .

In the lateral-directional dynamics, the roll mode has a time constant of $0.170 \mathrm{~s}$, which is classified as Level 1 for this mode. Dutch-roll mode is classified as Level 2 for cruise flight with an empty hopper, with the following characteristics:

- Natural frequency $\left(\omega_{S_{D R}}\right): 1.89 \frac{\mathrm{rad}}{\mathrm{s}}$;

- Damping factor $\left(\zeta_{S_{D R}}\right): 0.046$;

- $\omega_{S_{D R}} \zeta_{S_{D R}}: 0.0869$.

Spiral mode is classified as Level 1 for the cruise flight with an empty hopper since its time constant is equal to $109 \mathrm{~s}$. Translating the flight handling qualities for the Cooper-Harper scale, the aircraft attains Levels 4, 5 and 6, according to Table 3.

\section{DISCUSSION}

Regarding aerial spraying activities, it is essential for the aircraft to have a stable and steady flight even with significant mass variations. Thus, eliminating the pilot need to constantly correct its flight path.

For the presented UAV, $36 \%$ of its MTOW is of pesticides to be applied during the mission. Hence, it is essential to analyze the impact of this variation during flight. In addition, it was determined that none of the stable modes of the aircraft becomes unstable during operations due to the effects of inertia, CG and mass variations. Therefore, the UAV stability is unaffected by this mass variations.

In order to understand how the pilot feels handling of the projected UAV, the frequencies and damping of its modes were analyzed, generating the flight handling qualities grades. The obtained results were translated into a Cooper-Harper scale, where specific grades were found indicating a certain need for pilot intervention to keep the UAV's path and attitude as desired. These results are considered adequate for the presented case. Furthermore, the UAV's control characteristics are maintained during all the spraying activity, starting with a full hopper and ending it with an empty hopper.

\section{AUTHOR'S CONTRIBUTIONS}

Conceptualization: Mantovani LQ; Slongo AG; Moraes DD; Venturini MS; Data Curation: Mantovani LQ; Slongo AG; Moraes DD; Venturini MS; Formal Analysis: Mantovani LQ; Slongo AG; Investigation: Mantovani LQ; Slongo AG; Moraes DD; Venturini MS; Methodology: Mantovani LQ; Slongo AG; Project Administration: Mantovani LQ; Slongo AG; Moraes DD; Venturini MS; 
Resources: Slongo AG; Mantovani LQ; Software: Mantovani LQ; Slongo AG; Supervision: Mantovani LQ; Slongo AG; Moraes DD; Venturini MS; Validation: Mantovani LQ; Slongo AG; Visualization: Mantovani LQ; Slongo AG; Moraes DD; Writing — Original Draft Preparation: Mantovani LQ; Moraes DD; Slongo AG; Writing - Review \& Editing: Moraes DD; Slongo AG; Mantovani LQ.

\section{DATA AVAILABILITY STATEMENT}

Data will be available upon request.

\section{FUNDING}

This research received no specific grant from any funding agency in the public, commercial, or not-for-profit sectors.

\section{ACKNOWLEDGMENTS}

The authors are grateful to the Organization Committee of II Congresso Aeroespacial Brasileiro and to Dr André Luís da Silva for encouraging the development of this research work. We also thank the aerospace engineering faculty at the Federal University of Santa Maria for the support for the implementation of the conceive design implement operate (CDIO) methodology, which is related to the development of the project occasioning to this paper.

\section{REFERENCES}

Anand K, Goutam R (2019) An autonomous UAV for pesticide spraying. IJTSRD 3(3):986-990. https://doi.org/10.31142/ ijtsrd23161

Baughman C, Longeauay K (2015) Handling qualities evaluations of unmanned aircraft systems (No. 412TW-PA-15214). Air Force Test Center Edwards Air Force Base, California Air Force Materiel Command United States Air Force. https://doi. org/10.21236/ADA616887

[CBAP] Comissão Brasileira de Agricultura de Precisão (2013) Principais Conceitos e Expressões Utilizados na Agricultura de Precisão - AP. [accessed Sep. 9 2020]. https://www.gov.br/agricultura/pt-br/assuntos/sustentabilidade/tecnologia-agropecuaria/ agricultura-de-precisao-1/arquivos-de-agricultura-de-precisao/conceitos-relacionados-a-agricultura-de-precisao-1.pdf

Cook MV (2011) Flight Dynamics principles: a linear systems approach to aircraft stability and control. Oxford: Butterworth-Heinemann.

Cummings ML, Myers K, Scott SD (2006) Modified Cooper Harper evaluation tool for unmanned vehicle displays. Paper presented Proceedings of UVS Canada: Conference on Unmanned Vehicle Systems Canada. Canada.

Foster T, Bowman J (2005) Dynamic stability and handling qualities of small unmanned-aerial vehicles. Paper presented 43rd AIAA Aerospace Sciences Meeting and Exhibit. AIAA; Reno, Nevada, United States. https://doi.org/10.2514/6.2005-1023

Harper Junior RP, Cooper GE (1986) Handling qualities and pilot evaluation. J Guid Control Dyn 9(5):515-529. https://doi. org/10.2514/3.20142 
Jorge LAC, Inamasu RY, Carmo RB (2011) Desenvolvimento de um VANT totalmente configurado para aplicações em Agricultura de Precisão no Brasil. Paper presented XV Simpósio Brasileiro de Sensoriamento Remoto. SBSR; Curitiba, Paraná, Brazil.

Lan Y, Chen S (2018) Current status and trends of plant protection UAV and its spraying technology in China. Int J Precis Agric Aviat 1(1):1-9. https://doi.org/10.33440/j.ijpaa.20180101.0002

Oliveira S, Ludwig MP, Crizel RL, Lemes ES, Lucca Filho OA (2014) Amassamento durante o manejo do cultivo: efeito no rendimento e na qualidade de sementes de soja. Biosci J 30(4):1059-1069.

Slongo AG, Moraes DD, Mantovani LQ, Venturini MS (2019) Definição de requisitos de projeto para um veículo aéreo não tripulado (VANT) para pulverização agrícola. Paper presented II Congresso Aeroespacial Brasileiro. CAB; Santa Maria, Rio Grande do Sul, Brazil.

Tewari A (2007) Atmospheric and space flight dynamics: modeling and simulation with MATLAB ${ }^{\circledR}$ and Simulink ${ }^{\circledR}$ Boston: Birkhäuser. https://doi.org/10.1007/978-0-8176-4438-3

Williams W (2003) UAV Handling qualities.....you must be joking. Ipswich: Aerospace Sciences Corporation. 